\title{
Development of Sustained Release Preparations of Metoclopramide Hydrochloride Based on Fatty Matrix
}

\author{
Monnujan Nargis ${ }^{1}$, Md. Saiful Islam², Fatima Naushin ${ }^{3}$ \\ and Syed Shabbir Haider ${ }^{2}$
}

\author{
${ }^{1}$ Depaerment of Pharmacy, Jahangirnagar University, Savar, Dhaka 1342, Bangladesh. \\ ${ }^{2}$ Depaerment of Pharmaceutical Technology, Faculty of Pharmacy, University of Dhaka, \\ Dhaka 1000, Bangladesh. \\ ${ }^{3}$ Department of Pharmacy, The University of Asia Pacific, Dhanmondi, Dhaka 1209, Bangladesh.
}

\begin{abstract}
Sustained release formulations of metoclopramide $\mathrm{HCl}$ (4-amino-5-chloro- $N$-(2-diethylaminoethyl)-2methoxybenzamide hydrochloride) $(\mathrm{MH})$ were prepared using carnauba wax $(\mathrm{CW})$ and stearic acid (SA) as matrix formers. Granules were prepared by melt granulation method while direct compression technique was used to prepare the tablets. The drug release profiles of these products were studied by in-vitro dissolution testing in simulated gastric, gastrointestinal and intestinal media of $\mathrm{pH} 1.2,4.5$ and 7.5, respectively. The increase in the proportion of SA in the granules produced a concomitant decrease of the initial drug release rate but later on the release rate was enhanced in the intestinal medium. Drug release was found to be affected by compression force and stirring rate but also showed a dependency on $\mathrm{pH}$ of the dissolution fluid. The fastest release rate was found at $\mathrm{pH} 4.5$ and the slowest at $\mathrm{pH} 1.2$ which was consistent with the drug's solubility behavior. Matrix erosion and water uptake rates were highest in the intestinal medium and lowest in the gastric medium. The drug release kinetics followed the Higuchi's model in all cases.
\end{abstract}

Key words: Metoclopramide hydrochloride, sustained release tablets, melt granulation, direct compression, carnauba wax, stearic acid.

\section{INTRODUCTION}

Metoclopramide Hydrochloride (MH) is a commonly prescribed anti-emetic drug which is used for the treatment of nausea, vomiting associated with migraine, cancer therapy, surgery and pregnancy. ${ }^{1,2}$ The drug is readily absorbed from the gastrointestinal tract and after an oral dose, the maximum plasma concentration is reached in about 1.0 hour. ${ }^{3,4}$ It shows a good stability in acidic and alkaline medium but has a short half-life of 3-5 hours. ${ }^{1,5} \mathrm{MH}$ is usually given at a dose of $10-15 \mathrm{mg}$ for four times a day to maintain the effective blood concentration. It has been suggested that a sustained release (SR) preparation of $\mathrm{MH}$ designing for twice daily administration might be an advantageous dosage form, especially in long term therapy. ${ }^{3-6}$

Correspondence to: Syed Shabbir Haider Email: haidersyedshabbir@yahoo.com

Dhaka Univ. J. Pharm. Sci. 11(2): 129-136, 2012 (December)
The use of inert wax in matrix formation has been an advantageous technique and both granules and tablets can be prepared using inert wax materials. ${ }^{7-14}$ The mechanism of drug release from these types of matrix involves leaching out of the drug by the penetrating fluid. In addition, drugs coming out of the matrix through pores or crevices, are also dissolved in the dissolution media. ${ }^{7-9}$ Higuchi first treated the drug release from the matrix model by relating the percent release with square root of time and it has also been reported that matrix tablets prepared by using wax material may follow this model. ${ }^{15-19}$

So far, sustained release tablets of MH have been prepared using hydroxypropylmethylcellulose, carboxymethylcellulose sodium, chitosan, carbopol 981, crospovidone, croscarmellose sodium, etc. ${ }^{5,20}$ Our aim was to use less number of cheap, readily available raw materials and adopt simple techniques that can be utilized easily, even if used for 
commercial purpose. Preparations based on wax-lipid matrix were supposed to fulfill our requirements and, therefore, selected for investigation in the present study.

\section{MATERIALS AND METHODS}

Materials. Metoclopramide hydrochloride monohydrate BP (assay 104.48\% as $\mathrm{MH}$ ) was obtained from Sintopharm, Italy. Carnauba wax (CW), stearic acid (SA), povidone K30 (PK30), magnesium stearate (MS) and colloidal silicon dioxide (CSD) were collected from local pharmaceutical industries and were of pharmaceutical grade.

Preparation of SR MH tablets. The granules and tablets of $\mathrm{MH}$ were prepared according to the formulations shown in Table 1. The melt granulation method was applied for preparing the granules. ${ }^{9,11,17}$ The required amounts of $\mathrm{CW}$ and SA were mixed and melted at $85-90^{\circ} \mathrm{C}$. $\mathrm{MH}$ was incorporated in the molten mixture in small portions with continuous stirring at elevated temperature to achieve a homogenous distribution. After cooling, the solidified materials were pulverized and the granules thus obtained were sized by US standard sieves of the required mesh sizes to get the formulations F1, F2, F3 and F3a. For tablet preparation, method of mixing with release retarding agents followed by direct compression was adopted. ${ }^{21} \mathrm{CW}$ and SA (particles of 60/100 mesh size) were blended with MH (particles of $<100$ mesh size) for about 10 minutes. The required amounts of CSD and MS were added to this blend and mixed for few minutes. The mixtures were then compressed in a Carver laboratory press equipped with a $13 \mathrm{~mm}$ flat punch and die set at two compression forces to obtain the formulations F3b and F3c. Formulation F3d contained an additional amount of $10.5 \mathrm{mg} \mathrm{MH}$ as initial dose. This was incorporated in the matrix tablet by double compression method. ${ }^{22}$ After preparation of the SR core (F3b), the upper punch was withdrawn and a blend of MH and PK30 was fed into the die over the compressed mass and recompression was performed at a pressure of 0.5 metric ton. All the preparations were stored in airtight containers at ambient condition until further studies.

Differential scanning calorimetry. Differential scanning calorimetric (DSC) analysis was performed with a Perkin-Elmer instrument fitted with and graphics plotter (Model DSC 7, TAC 7/DX). Scanning rate was $10^{\circ} \mathrm{C} /$ minute and sample weights were about $5 \mathrm{mg}$.

Physical characterization of designed tablets. Tablet thickness and hardness were determined for 6 tablets using a Dr. Schleuniger Pharmatron Tablet Tester 8M (UK).

Determination of matrix erosion and water uptake rate. The method of Sutananta et al. ${ }^{23}$ was employed for measuring matrix erosion and water erosion uptake rates in different simulated media. ${ }^{23}$ For this study, matrix tablets were prepared with composition similar to $\mathrm{F} 3 \mathrm{~b}$ without $\mathrm{MH}$.

In vitro dissolution studies. In vitro release study of $\mathrm{MH}$ from the granules and tablets was conducted using a six station USP type II apparatus at $37 \pm 0.5^{\circ} \mathrm{C}$ and $\mathrm{rpm}$ was set at 50 . One tablet or the weight of granules equivalent to $20 \mathrm{mg}$ of $\mathrm{MH}$ was placed in the basket. The dissolution media were 900 $\mathrm{ml}$ USP simulated gastric medium of $\mathrm{pH} 1.2$ (SGM) for the first $1 \mathrm{~h}, 900 \mathrm{ml}$ simulated gastrointestinal medium of $\mathrm{pH} 4.5$ (SGIM) for the next 1 hour followed by $900 \mathrm{ml}$ USP simulated intestinal medium of $\mathrm{pH} 7.5$ (SIM) for the next 10 hours (from $3^{\text {rd }}$ to $12^{\text {th }} \mathrm{h}$ ). The SGIM was prepared by mixing SGM and SIM in appropriate proportion. ${ }^{23}$ The effect of $\mathrm{pH}$ on release of $\mathrm{MH}$ from the preparations was examined in case of F3b by performing dissolution experiments in three simulated media (SGM, SGIM, SIM) separately maintaining the same dissolution conditions mentioned above. In addition of $50 \mathrm{rpm}$, dissolution was also performed for F $3 \mathrm{~b}$ at $100 \mathrm{rpm}$ and $150 \mathrm{rpm}$ of paddle rotation speed. All dissolution experiments were conducted in triplicate.

Quantification of $\mathrm{MH}$ in the dosage forms and in dissolution media. One $\mathrm{MH}$ tablets or $\mathrm{MH}$ granules equivalent to $20 \mathrm{mg}$ of anhydrous metoclopramide hydrochloride was taken and 
crushed into fine powder. The powder was transferred in a clean, dry $100 \mathrm{~mL}$ volumetric flask and $50 \mathrm{ml}$ of $0.1 \mathrm{~N} \mathrm{HCl}$ was added and sonicated in an ultrasonic water bath for 30 minutes with occasional swirling. The sample was allowed to cool down at room temperature and the volume was made up to $100 \mathrm{~mL}$ by the same diluent. Then after appropriate dilutions (if necessary), $\mathrm{MH}$ content was measured by UV Spectrophotometer (Shimadzu, model UV-160A, Japan) at $309 \mathrm{~nm}$. Similar UV spectrophotometric method was followed for the analysis of dissolution samples.

\section{RESULTS AND DISCUSSION}

The maintenance dose, incorporated within the matrix, was calculated on the basis of pharmacokinetic data available for the drug. ${ }^{1,24}$ Considering a zero order release at a rate of 1.54 $\mathrm{mg} /$ hour, the maintenance dose for a 12 hour period was calculated to be $18.5 \mathrm{mg}$ of $\mathrm{MH} .^{25}$ However, considering the reduced bioavailability of the drug due to hepatic first pass metabolism and the probability of incomplete release from fat matrix, a somewhat greater amount $(20 \mathrm{mg}$ of $\mathrm{MH}$ equivalent to $21 \mathrm{mg}$ of metoclopramide hydrochloride monohydrate BP) was taken as the maintenance dose. $^{1,26}$ Practically, an ideal zero order release is very difficult to achieve but drug delivery systems having release characteristics other than zero order can still be therapeutically active and fulfill the desired goal if designed properly. ${ }^{26}$

Metoclopramide hydrochloride granules and tablets were prepared considering different formulation variables such as variation in granule size, release modifier, compression force and these are shown in table 1 . Table 2 shows the tabletting properties and drug contents of the $\mathrm{MH}$ granules and tablets. Uniform drug content was found in both the granule and tablet formulations. An increase in the compression forces from $\mathrm{F} 3 \mathrm{~b}$ to $\mathrm{F} 3 \mathrm{c}$ resulted in low thickness and high hardness values. Solid state solubility of $\mathrm{MH}$, matrix erosion and water uptake of $\mathrm{MH}$ tablets are shown in table 3. Good solubility of $\mathrm{MH}$ was observed in case of simulated SGIM at $\mathrm{pH}$ 4.5. In contrast, maximum matrix erosion and water uptake values were found for simulated SIM at $\mathrm{pH}$ 7.5 .

Table 1. Formulations of granules and tablet matrices of metoclopramide hydrochloride.

\begin{tabular}{|c|c|c|c|c|c|c|c|c|}
\hline \multirow{2}{*}{\multicolumn{2}{|c|}{ Variables }} & \multicolumn{7}{|c|}{ Formulation identity } \\
\hline & & $\mathrm{F} 1$ & $\mathrm{~F} 2$ & F3 & F3a & $\mathrm{F} 3 \mathrm{~b}$ & $\mathrm{~F} 3 \mathrm{c}$ & F3d* \\
\hline \multicolumn{2}{|c|}{ Ratio of CW:SA:MH } & $7: 0: 1$ & $7: 2.5: 1$ & $7: 5: 1$ & $7: 5: 1$ & $7: 5: 1$ & $7: 5: 1$ & $7: 5: 1$ \\
\hline \multicolumn{2}{|c|}{$\begin{array}{l}\text { Granule size } \\
\text { (sieve no. passed/ retained) } \\
\text { Amount per tablet (mg) CW }\end{array}$} & $20 / 30$ & $20 / 30$ & $20 / 30$ & $10 / 14$ & - & - & - \\
\hline \multirow[t]{3}{*}{ Amount per tablet (mg) } & $\mathrm{CW}$ & - & - & - & - & 147 & 147 & 147 \\
\hline & SA & - & - & - & - & 105 & 105 & 105 \\
\hline & МHH & - & - & - & - & 21 & 21 & 21 \\
\hline \multirow[t]{3}{*}{ Other ingredients (mg) } & CSD & - & - & - & - & 1 & 1 & 1 \\
\hline & MS & - & - & - & - & 2 & 2 & 2 \\
\hline & PK30 & - & - & - & - & - & - & 40 \\
\hline \multirow{2}{*}{\multicolumn{2}{|c|}{$\begin{array}{l}\text { Compression force } \\
\text { (metric ton) }\end{array}$}} & - & - & - & - & - & 6 & Initially 2 \\
\hline & & - & - & - & - & - & & Finally 0.5 \\
\hline
\end{tabular}

* Formulation F3d also contains an additional amount of $10.5 \mathrm{mg}$ of $\mathrm{MH}$ as initial dose besides $21.0 \mathrm{mg}$ of the maintenance dose.

Table 2. Drug content and properties of the prepared dosage forms.

\begin{tabular}{|c|c|c|c|c|c|c|}
\hline Dosage form & Formulation identity & $\begin{array}{c}\text { Drug loaded } \\
(\mathrm{mg})^{*}\end{array}$ & $\begin{array}{l}\text { Drug found } \\
(\mathrm{mg})^{*}\end{array}$ & $\begin{array}{c}\text { Weight } \\
(\mathrm{mg})\end{array}$ & $\begin{array}{c}\text { Thickness } \\
(\mathrm{mm})\end{array}$ & $\begin{array}{c}\text { Hardness } \\
(\mathrm{kg})\end{array}$ \\
\hline \multirow{4}{*}{ Granules } & F1 & 20 & 18.20 & - & - & - \\
\hline & $\mathrm{F} 2$ & 20 & 18.86 & - & - & - \\
\hline & F3 & 20 & 19.60 & - & - & - \\
\hline & $\mathrm{F} 3 \mathrm{a}$ & 20 & 19.60 & - & - & - \\
\hline \multirow{3}{*}{ Tablets } & F3b & 20 & 19.92 & 272.68 & 2.33 & 5.40 \\
\hline & $\mathrm{F} 3 \mathrm{c}$ & 20 & 19.55 & 271.87 & 2.19 & 7.00 \\
\hline & F3d & 30 & 29.92 & 324.33 & 2.47 & 6.75 \\
\hline
\end{tabular}

* Calculated on anhydrous basis (MH). 
Figure 1 shows the DSC thermograms where peak of pure $\mathrm{MH}, \mathrm{SA}, \mathrm{CW}$ and powdered sample of $\mathrm{F} 3 \mathrm{~b}$ are shown. $\mathrm{SA}, \mathrm{CW}$, and $\mathrm{MH}$ showed their respective peak at 55,86 and $92^{\circ} \mathrm{C}$, respectively. Figure 1D represents the endothermic peak of the optimized batch where sharp peak at around $51^{\circ} \mathrm{C}$ and little round peak at around $74^{\circ} \mathrm{C}$ were found. Peak around $74^{\circ} \mathrm{C}$ was rather little stretched ranging from $68^{\circ} \mathrm{C}$ to $82^{\circ} \mathrm{C}$ which might be due to combined peak of $\mathrm{CW}$ and $\mathrm{MH}$. Since $\mathrm{MH}$ has a very high melting point $\left(183^{\circ} \mathrm{C}\right)$, the endothermic peak at around $92^{\circ} \mathrm{C}$ in curve $\mathrm{C}$ is probably due to the transition of the drug to the anhydrous form via loss of one mole water. It is clearly observed from the thermogram of the powdered matrix (curve D) that the drug peak has been disappeared and the peak for

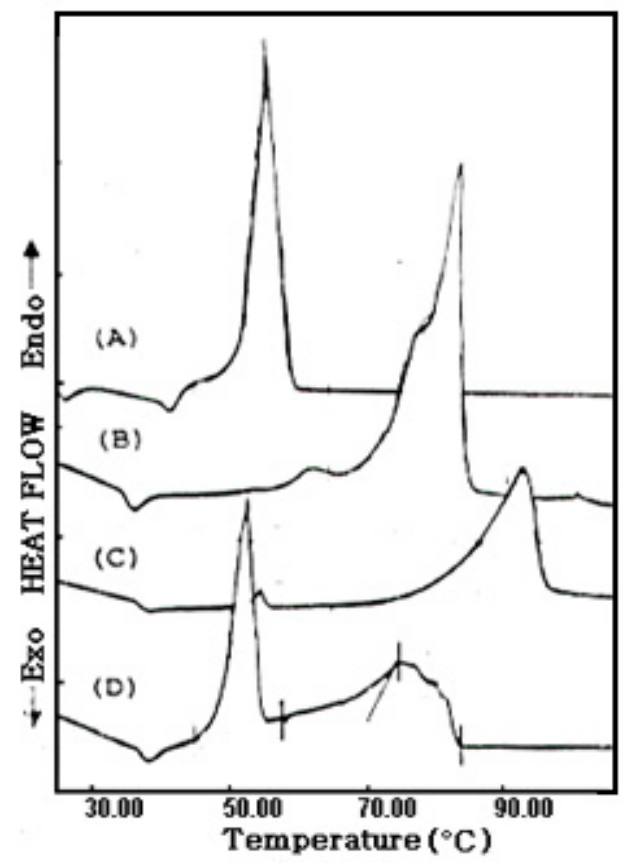

Figure 1. DSC thermograms of matrix and its formulation components: (A) SA (B) CW (C) MH (D) Powdered sample of tablets coded $\mathrm{F} 3 \mathrm{~b}$ containing $\mathrm{SA}, \mathrm{CW}$ and $\mathrm{MH}$.

$\mathrm{CW}$ has been distorted and broadened to a considerable extent. But the peak for SA is almost unaffected. IR studies also revealed the absence of some of the characteristic absorption bands of the functional groups of $\mathrm{MH}\left(3410 \mathrm{~cm}^{-1}, \mathrm{~N}-\mathrm{H}\right.$ stretching of secondary amide; $3350 \mathrm{~cm}^{-1}$, N-H stretching of primary amine) in the IR spectrum of powdered sample of the prepared tablets (spectra not shown). The results of the DSC and IR studies are indicative of some sort of complex formation between the drug and carnauba wax. The presence of multifunctional groups in metoclopramide molecule as well as the complex nature of carnauba wax comprising mostly of esters of higher fatty acids and alcohols, suggest the probable existence of such interaction. Nevertheless, the exact nature of the interaction is quite difficult to be ascertained from these preliminary findings.

Figure 2 shows the percent release of $\mathrm{MH}$ from F1-F3a (Figure 2A) and F3b-F3d (Figure 2B) where the dissolution was conducted in three different dissolution media. Considering first $5 \mathrm{hrs}$ of dissolution, slowest release was observed for F3 and fastest release was observed for F1 where dissolution media was SGF and SGIF e.g. release rate was in the following decreasing order: $\mathrm{F} 3>\mathrm{F} 2>\mathrm{F} 1$. But from the $6^{\text {th }}$ hour of dissolution, release was found to follow the reverse order of dissolution e.g. the order was in the following decreasing order $\mathrm{F} 1>\mathrm{F} 2>\mathrm{F} 3$. However, release of $\mathrm{MH}$ from $\mathrm{F} 3 \mathrm{a}$ was the slowest of all. Release curve of this batch was also similar to that of the theoretical zero order release curve having a release rate of $1.54 \mathrm{mg} /$ hour. On the other hand, figure $2 \mathrm{~B}$ represents the release of $\mathrm{MH}$ from the optimized tablet formulations of F3b, F3c and F3d. Release pattern of $\mathrm{MH}$ from $\mathrm{F} 3 \mathrm{~b}$ and $\mathrm{F} 3 \mathrm{c}$, where two compression forces of 2 and 4 metric tons were used respectively, was almost superimposable to each other. Formulation F3d contained an extra loading dose of 10.5 and it also showed an ideal zero-order release curve similar to that of a theoretical one which is common for tablets containing both loading dose and maintenance dose.

A decrease in the initial release rate of $\mathrm{MH}$ from the optimized granules was found while the SA content in the matrix was increased (Figure 2A). This might be due to the increase in the amount of total materials causing retardation. But release pattern was found to be totally reversed from the sixth hours of 

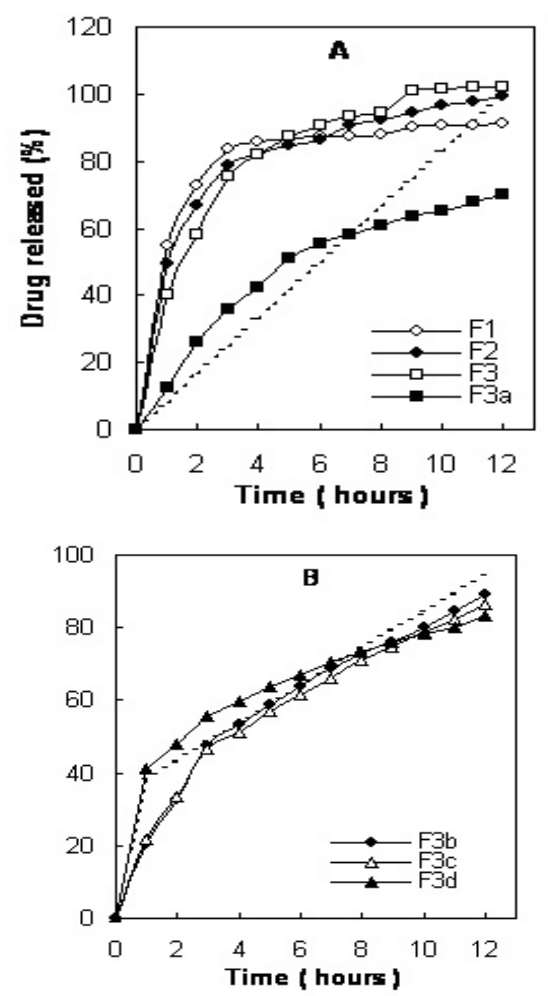

Figure 2. Mean $(\mathrm{n}=3$, S.D. $<1.0)$ dissolution profiles of $\mathrm{MH}$ for various formulations; (A) Granules. The dotted line indicates a theoretical zero-order release process with a rate of 1.54 $\mathrm{mg}$ /hour (B) Tablets. The dotted line indicates a theoretical rapid release of $10 \mathrm{mg}$ followed by a zero-order release process with a rate of $1.54 \mathrm{mg} /$ hour. dissolution. Release rate started to be increased from F3 (containing the highest amount of SA) whereas release from F1 (containing no SA) started to be slowed down gradually. This may be due to the fact that SA might remain totally unionized in the acidic $\mathrm{pH}$ of SGM ( $\mathrm{pH} 1.2)$ as it is a weak acid and therefore making the matrix compact and impervious to the surrounding fluid. In addition, SA is more soluble in SIM than SGM. Being soluble in SIM, SA might form anionic stearate surfactant with SIM and the higher solubility of SA in SIM induced greater matrix erosion and higher water uptake rate in formulation F3 (Table 3). The compositions of formulation F3 and F3a are same except that the latter has an increased granule size which eventually resulted in a decrease in the rate and extension of drug release (Figure 2A). Larger granule size might cause the $\mathrm{MH}$ molecule to travel a longer distance in the granules and this eventually delayed the release of the drug from F3a.

Table 3. Solubility of MH, matrix erosion rate and water uptake rate in various dissolution media

\begin{tabular}{ccccc}
\hline Medium & $\mathrm{pH}$ & Solubility $(\mathrm{mg} / \mathrm{ml})$ & $\begin{array}{c}\text { Matrix erosion rate } \\
(\% / \text { hour })^{*}\end{array}$ & $\begin{array}{c}\text { Water uptake rate } \\
\text { (\%/hour)* }\end{array}$ \\
\hline SGM & 1.2 & 630.22 & 0.032 & 0.214 \\
SGIM & 4.5 & 697.17 & 0.046 & 0.263 \\
SIM & 7.5 & 670.39 & 0.074 & 9.270 \\
\hline
\end{tabular}

*These values are for formulation F3b
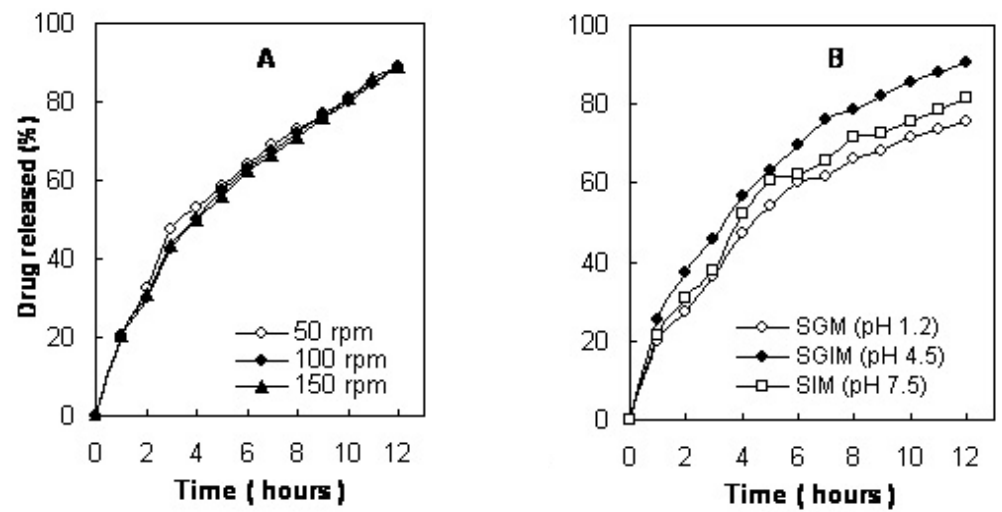

Figure 3. Mean ( $n=3$, S.D. < 1.4 ) dissolution profiles of MH for formulation F3b ; (A) Effect of various paddle stirring rates (B) Effect of various simulated dissolution media. 
From figure $2 \mathrm{~B}$, it is evident that $\mathrm{MH}$ release from F3b and F3c was nearly identical and this suggests about the fact that compression force had no effect on the ultimate release of $\mathrm{MH}$ from tablets. From here, it can be inferred that rather than compression force, these are the matrix erosion, water uptake, $\mathrm{pH}$ solubility properties which play the pivotal role in controlling the release of a drug from matrix tablets. ${ }^{10}$ The test tablets, although became somewhat soft, did not change their shape after the experimental time period. These findings suggest that the composition of F3b may be considered as an ideal one to prepare sustained release tablets of $\mathrm{MH}$. These findings are in close agreement with those of other experiments. ${ }^{27,28}$

Figure 3A represents the release curves of $\mathrm{MH}$ from $\mathrm{F} 3 \mathrm{~b}$ where dissolution was conducted in three different paddle rotation speeds, 50, 100 and 150 rpm. No significant influence of different paddle speed was found on release property of the drug. Figure 3B shows the release curves of $\mathrm{MH}$ where dissolution was conducted using three different media, SGM of $\mathrm{pH} 1.2$, SGIM of $\mathrm{pH} 4.5$ and SIM of $\mathrm{pH}$ 7.5. In this case, $\mathrm{pH}$ dependent release curves were found and the release rate was found in the following decreasing order: SGM $<$ SIM $<$ SGIM i.e. the release rate of the drug was the highest in SGIM

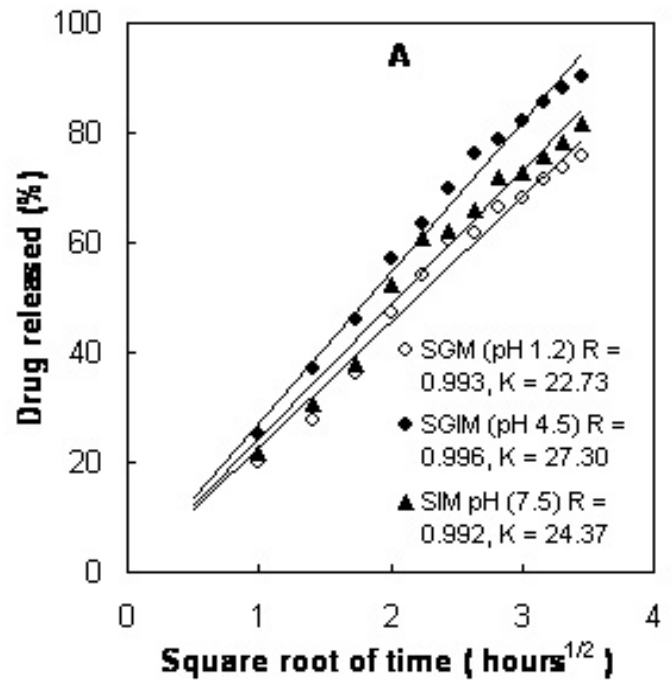

( $\mathrm{pH} 4.5)$, intermediate in SIM (pH 7.5) and lowest in SGM (pH 1.2). The solubility of MH in these three media also follows the same pattern (Table 3). The drug, being a salt of a weak base $(\mathrm{pKa}=9.0)$, is supposed to be soluble mostly in the acidic $\mathrm{pH}$ of SGM and least in the alkaline $\mathrm{pH}$ of SIM. But practically it was found that its solubility order was as follows: SGIM > SIM > SGM. Timko and Lordi ${ }^{29}$ also observed similar behavior in case of Papaverine $\mathrm{HCl}$. The data indicates a significant common ion effect due to the presence of excess chloride, which significantly reduced the solubility and dissolution of the hydrochloride salt in SGM. On the other hand, the matrix erosion and water uptake rates were the highest in SIM and lowest in SGM as mentioned earlier. Thus, solubility has a profound effect on drug release over matrix erosion and water uptake. Nevertheless, in pH-changing dissolution experiments, which closely simulate in vivo situation, overall release characteristics will be more influenced by the intestinal $\mathrm{pH}$ since residence time is much longer in SIM then in SGM or SGIM. This is particularly more applicable for the test drug as it has the property of increasing gastrointestinal motility causing less residence time in the stomach and upper intestine. ${ }^{1}$

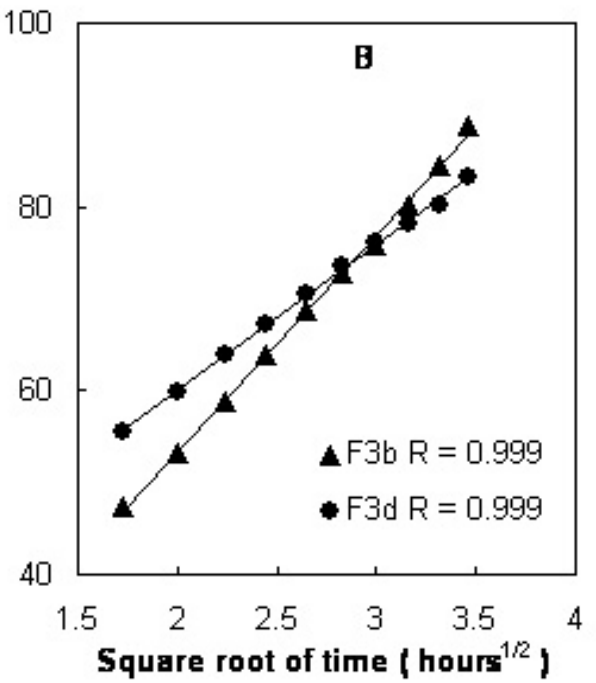

Figure 4. Higuchi plots of drug release from tablets. Linear regression lines, correlation coefficients (R) and Higuchi rate constants (K, percent drug released / hour ${ }^{0.5}$ ) are included. (A) For formulation F3b in various simulated media. (B) For formulation F3b and F3d excluding the data for the first three hours release. 
The kinetics of drug release in different simulated media were determined by using several mathematical models. The Higuchi's square root of time model (amount of drug released is directly proportional to square root of time) showed the best fit for the release data. The Higuchi plots of drug release in different simulated media are shown in figure 4A. This type of drug release kinetics is frequently observed in case of wax-lipid matrices and has been extensively reported by various workers. ${ }^{10,11,19,21,28}$

Figure 2B also depicts the dissolution profile of the tablets of formulation F3d which contain both initial dose $(10 \mathrm{mg})$ and maintenance dose $(20 \mathrm{mg})$ of MH. From the figure, it is observed that a rapid release of the drug (about 40\%) was achieved within one hour due to the presence of initial dose in the formulation. After that, an almost linear release was maintained up to the end of the experimental period. The total drug content was not released within 12 hours and about $20 \%$ drug remained in the matrix after the experimental time period. The same Higuchi square root of time model was found to be the most appropriate in explaining the drug release from the tablets of formulation F3d as well as the parent formulation F3b. However, the release pattern of the drug for the first three hours was somewhat found to deviate from this behavior, probably due to the change of $\mathrm{pH}$ of the dissolution medium occurring at this time and also due to the initial rapid release of the drug. Figure 4B depicts the Higuchi plots of drug release for F3b and F3d for the last nine hours of dissolution. The matrix erosion rate was not as high as was understood from the data given in table 3 . Therefore, the release was not so much erosion controlled. On the other hand, the tremendous water uptake in SIM suggested that water penetration and subsequent leaching of the drug due to good solubility in this medium from the matrix played the dominant role in drug release besides the simple diffusion process.

\section{CONCLUSION}

In view of the above findings, it can be suggested that CW-SA matrix may be employed successfully for the development of SR tablets of $\mathrm{MH}$. The release retarding materials are cheap, readily available, safe and easy to handle. The method of preparation of SR tablets utilizes minimum machinery and manpower. From the economical viewpoint, it may be beneficial for the local pharmaceutical companies to adopt such simple technologies for the preparation of SR products of $\mathrm{MH}$.

\section{ACKNOWLEDGEMENTS}

The authors are thankful to Renata Pharmaceuticals Ltd. (formerly Pfizer Bangladesh Ltd.), Dhaka, Bangladesh for providing most of the instrumental facilities. We also express our gratitude towards Syed Md. Shahriyar, Product Development Pharmacist, Barr Laboratories, USA for providing DSC facilities.

\section{REFERENCES}

1. Brunton, L.L. 1991. Agents affecting gastrointestinal water flux motility, digestants and bile acids. In: Gilman AG, Rall TW, Nies AS, Taylor P editors. The Pharmacological Basis of Therapeutics, Volume 2, $8^{\text {th }}$ ed., Pergamon Press: Singapore. pp. 926-928.

2. Mcevoy, G. 1991. Miscellaneous GI drugs; In: American Hospital Formulary Service-Drug Information, Bethesda, MD: American Society of Hospital Pharmacists, Inc. pp. 1765-1771

3. Bateman, D.N. 1983. Clinical Pharmacokinetics of metoclopramide. Clin Pharmacokinet. 8, 523-529.

4. El-Sayed, Y.M., Niazy, E.M. and Khidr, S.H. 1995. In-vivo evaluation of sustained release microspheres of metoclopramide hydrochloride in beagle dogs. Int. J. Pharm. 123, 113-118.

5. Savaşer, A., Taş, C., Bayrak, Z., Ozkan, C.K. and Ozkan, Y. 2012. Effect of different polymers and their combinations on the release of metoclopramide $\mathrm{HCl}$ from sustained-release hydrophilic matrix tablets. Pharm. Dev. Technol. [Epub ahead of print, PMID: 22881478]

6. El-Sayed, Y.M., Niazy, E.M. and Khidr, S.H. 1995. Preparation and in vitro evaluation of sustained release metoclopramide hydrochloride microspheres. J. Microencapsul. 12, 651-660. 
7. El-Shanawany, S.J. 1993. Sustained release of nitrofurantoin from inert wax matrix. J. Control. Rel. 26, 11-19.

8. Dakkuri, A., Schroeder, H.G., Deluca, P.P. 1978. Sustained release from inert wax matrixes II-effect of surfactants on tripelennamine hydrochloride release. J. Pharm. Sci. 67, 354357.

9. Emori, H., Ishizaka, T. and Koishi, M. 1984. Effects of acrylic acid polymer and its arrangement on drug release from a wax matrix. J. Pharm. Sci. 73, 910-5.

10. Goodhart, F.W., McCoy, R.H. and Ninger, F.C. 1974. Release of a water soluble drug from a wax matrix timed release tablet. J. Pharm. Sci. 63, 1748-1751.

11. Foster, T.P. and Parrott, E.L. 1990. Release of highly water soluble medicinal compounds from inert heterogeneous matrixes-melt. J. Pharm. Sci. 79, 938-942.

12. Llabres, M. and Farina, J.B. 1990. Design and evaluation of sustained release tablets of lithium in a fat matrix and its bioavailability in humans. J. Pharm. Sci. 80, 1012-1016.

13. Huang, H., Mehta, S.C., Radebaugh, G.W. and Fawzi, M.B. 1994. Mechanism of drug release from an acrylic polymerwax matrix tablet. J. Pharm. Sci. 83, 795-797.

14. Otsuka, M. and Matsuda, Y. 1994. Effect of co-grinding time on the release of pentoxifylline from waxy matrix tablets. $J$. Pharm. Sci. 83, 956-961.

15. Higuchi, T. 1963. Mechanism of sustained action medication. J. Pharm. Sci. 52, 1145-1149.

16. Ishino, R. and Sunada, H. 1993. Studies on application of wax matrix system for controlled drug release. Chem. Pharm. Bull. 41, 586-589.

17. Ishino, R., Yushino, H., Hirakawa, Y. and Noda, K. 1991. Influence of compression force on consolidation behavior and drug release property of wax matrix tablets. Chem. Pharm. Bull. 39, 3318-3322.

18. Ishino, R., Yushino, H., Hirakawa, Y. and Noda, K. 1990. Influence of internal structure on kinetics of drug release from wax matrix tablets. Chem. Pharm. Bull. 38, 3440-3445.
19. Schwartz, J.B., Simonelli, A.P. and Higuchi, W.I. 1968. Drug release from wax matrices. J. Pharm. Sci. 57, 274-277.

20. Kasliwal, N., Negi, J.S., Jugran, V. and Jain, R. 2011. Formulation, development, and performance evaluation of metoclopramide $\mathrm{HCl}$ oro-dispersible sustained release tablet. Arch. Pharm. Res. 34, 1691-700.

21. Foster, T.P. and Parrott, E.L. 1990. Release of highly water soluble medicinal compounds from inert heterogeneous matrixes- Physical mixture. J. Pharm. Sci. 79, 806-810.

22. Bandelin, F.J. 1989. Compressed tablets by wet granulation. In: Lieberman HA, Lachman L. and Schwartz JB eds. Pharmaceutical Dosage Forms: Tablets, Volume $1,2^{\text {nd }}$ ed., New York and Basel: Marcel Dekker Inc. p.185.

23. Sutananta, W., Craig, D.Q.M. and Newton, J.M. 1995. An evaluation of the mechanism of drug release from glyceride bases. J. Pharm. Pharmacol. 47, 182-187.

24. Clarke. 1986. Clarke's Isolation and Identification of Drugs, $2^{\text {nd }}$ ed., The Pharmaceutical Press, London, pp. 776-777.

25. Chowdhury, D.K., Khare, R.L. and Santani, D.D. 1989. Sustained release microcapsules as drug delivery system for amitriptyline hydrochloride. J. Bang. Acad. Sci. 13, 151-155.

26. Lordi, N.G. 1990. Sustained release dosage forms. In: Lachman L, Lieberman HA, Kanig JL eds. The Theory and Practice of Industrial Pharmacy, $3^{\text {rd }}$ ed., Varghese Publishing House: Bombay; pp. 430-456.

27. Akiyama, Y., Yoshioka, M., Hirai, S., Kitamori, N. and Toguchi, H. 1994. pH Independent controlled release microspheres using polyglycerol esters of fatty acids. $J$. Pharm. Sci. 83, 1600-1607.

28. Prapaitrakul, W., Sprockel, O.L. and Shivanand, P. 1991. Release of chlorpheniramine maleate from fatty acid ester matrix disks prepared by melt extrusion. J. Pharm. Pharmacol. 43, 377-378.

29. Timko, R.J. and Lordi, N.G. 1978. In vitro evaluation of three commercial sustained release papaverine hydrochloride products. J. Pharm. Sci. 67, 496-500. 